\title{
Risk predictive role of hypernatremia for occurrence of sepsis- induced acute kidney injury
}

\author{
Deyuan Zhi, Jin Lin, Lei Dong, Xiaojun Ji, Haizhou Zhuang, Zhuang Liu, Jingfeng Liu, Meili Duan \\ Department of Critical Care Medicine, Beijing Friendship Hospital, Capital Medical University, Beijing, China \\ Contributions: (I) Conception and design: D Zhi, M Duan; (II) Administrative support: D Zhi, M Duan; (III) Provision of study materials or patients: \\ Deyuan Zhi, M Zhang, Y Wang; (IV) Collection and assembly of data: D Zhi, M Zhang, Y Wang; (V) Data analysis and interpretation: J Lin, P Liu; \\ (VI) Manuscript writing: All authors; (VII) Final approval of manuscript: All authors. \\ Correspondence to: Meili Duan. Department of Critical Care Medicine, Beijing Friendship Hospital, Capital Medical University, 95 Yong'an Road, \\ Xicheng District, Beijing 100050, China. Email: dmeili@ccmu.edu.cn
}

\begin{abstract}
Background Septic acute kidney injury (AKI), identified when sepsis and AKI present concurrently, is a syndrome of acute function impairment and organ damage, which accounts for $\sim 50 \% \mathrm{AKI}$ in the intensive care unit (ICU).

Methods: This study retrospectively reviewed 591 patients who were diagnosed with sepsis and admitted to the ICU of Beijing Friendship Hospital from January 2009 to December 2014. According to the concentration of serum sodium, the 591 patients were further divided into 3 groups: normal group, hyponatremia group, and hypernatremia group.

Results: The arterial partial pressure of carbon dioxide $\left(\mathrm{PaCO}_{2}, \mathrm{P}=0.014\right)$, concentration of sodium $\left(\mathrm{Na}^{+}\right.$, $\mathrm{P}<0.001$ ), and chloride ion $\left(\mathrm{Cl}^{-}, \mathrm{P}<0.001\right)$, blood urea nitrogen (BUN, $\mathrm{P}<0.001$ ), acute physiology and chronic health evaluation (APACHE) score $(\mathrm{P}<0.001)$, sequential organ failure assessment (SOFA) score $(\mathrm{P}<0.001)$, and Glasgow score $(\mathrm{P}<0.001)$ showed significant differences. The SOFA score $[\mathrm{P}=0.040$; odds ratio $(\mathrm{OR})=1.261$, body mass index $(\mathrm{BMI}, \mathrm{P}=0.041 ; \mathrm{OR}=1.229), \mathrm{P}$ content $(\mathrm{P}=0.032 ; \mathrm{OR}=7.180)$ and creatine kinase myocardial band $(\mathrm{CK}-\mathrm{MB}, \mathrm{P}=0.006$; $\mathrm{OR}=1.168)$ may be risk factors for occurrence of AKI in patients with hypernatremia. The AKI $(\mathrm{P}<0.001$; $\mathrm{OR}=6.850)$ and $\mathrm{P}$ content $(\mathrm{P}=0.027 ; \mathrm{OR}=3.676)$ may be risk factors for death in patients with hypernatremia. The $\mathrm{Na}^{+}$suggested a predictive ability for $\mathrm{AKI}(\mathrm{P}<0.001$; area under the curve (AUC): 0.586) but not for death $(\mathrm{P}=0.104)$.
\end{abstract}

Conclusions: Hypernatremia is independently associated with an increased risk and has a predictive ability of AKI in patients with sepsis.

Keywords: Hypernatremia; acute kidney injury; sepsis; sodium

Submitted Feb 24, 2021. Accepted for publication Apr 21, 2021.

doi: 10.21037/apm-21-792

View this article at: http://dx.doi.org/10.21037/apm-21-792

\section{Introduction}

Sepsis is a systemic and deleterious host response, which engenders severe sepsis and septic shock, with mortality of more than $25 \%(1,2)$. The progress of this disease could further deteriorate with the occurrence of subsequent acute organ dysfunction or combination with hypotension that is not reversed with fluid resuscitation $(3,4)$. Among critically ill patients, sepsis is thought to be the most common cause of severe acute kidney injury (AKI) $(5,6)$. Septic AKI, identified when both sepsis and AKI present, is a syndrome of acute function impairment and organ damage, accounting for $\sim 50 \%$ AKI cases in the intensive care unit (ICU) $(7,8)$. The hospital mortality is $47 \%$ and 1 -year survival is only $77 \%$ for patients with stage 2-3 AKI that does not resolve within 7 days (8). Previous studies have confirmed that many complex factors were associated with the occurrence of AKI, including smoking history, diabetes, hypertension, 


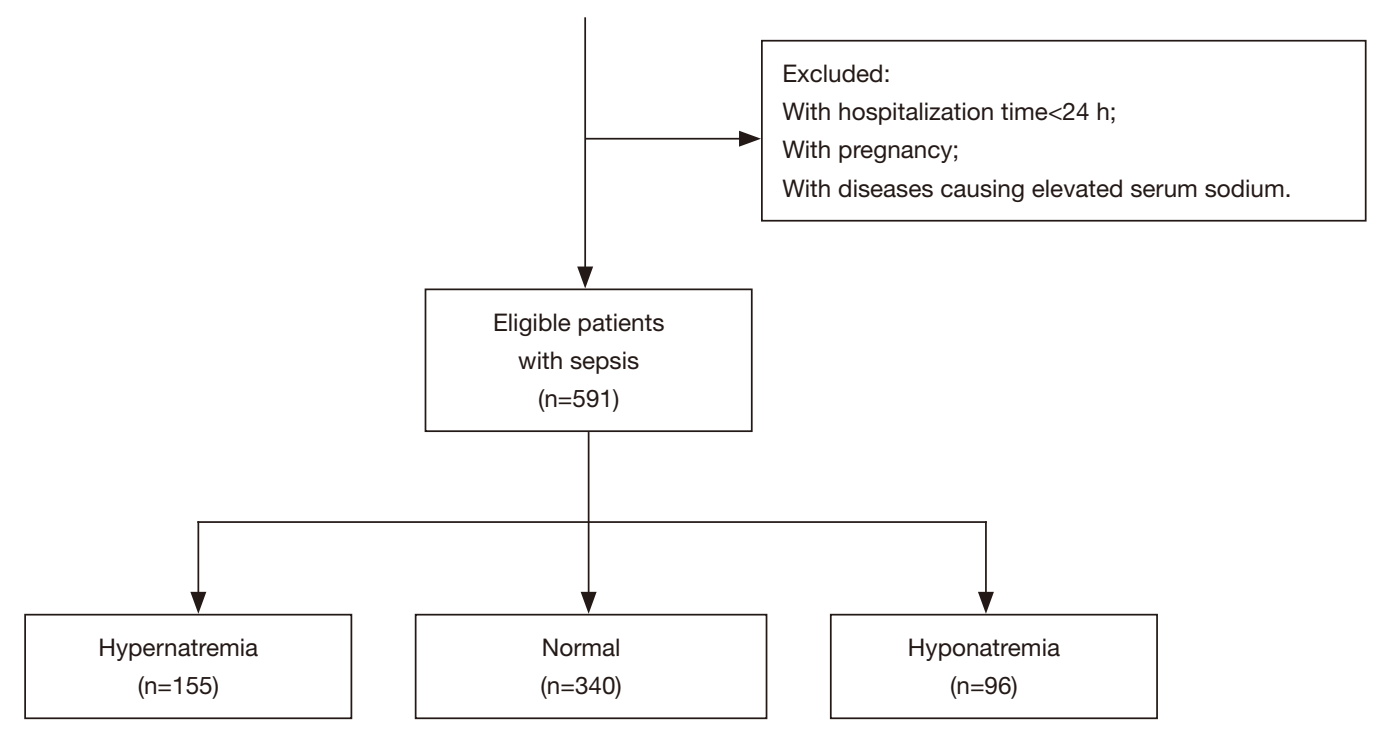

Figure 1 Flow chart of patients involved in this study

abdominal infection, and so on (9). Although advances have been made in modern diagnostic methods, limitations in specificity and sensitivity impede advances in research and clinical applications.

Hypernatremia, defined as the concentration of sodium $\left(\mathrm{Na}^{+}\right)>145 \mathrm{mmol} / \mathrm{L}$, is one of the most common electrolyte disorders among patients who are critically ill $(10,11)$. In clinical practice, hypernatremia is a frequent condition of life-threatening potential and found to occur in $9 \%$ of ICU patients $(12,13)$. Hypernatremia can cause peripheral insulin resistance, hepatic gluconeogenesis impairment, neuropsychiatric impairment, cardiac contractility dysfunction, and so on (13). However, only a limited number of studies have focused on hypernatremia. Rather than just an alternative marker of disease severity, hypernatremia may be a prognostic risk factor for the development of AKI. Therefore, we evaluated the predictive and prognostic role of hypernatremia for AKI in patients with sepsis.

We present the following article in accordance with the STARD reporting checklist (available at http://dx.doi. org/10.21037/apm-21-792).

\section{Methods}

\section{Population}

This study retrospectively reviewed 591 patients who were diagnosed with sepsis and admitted to the ICU of Beijing
Friendship Hospital from January 2009 to December 2014. Patients who were hospitalized in the ICU for less than $24 \mathrm{~h}$, pregnant, and suffering from diseases causing elevated serum $\mathrm{Na}^{+}$such as primary aldosteronism and hypercortisolism were excluded. According to the concentration of serum $\mathrm{Na}^{+}$, the 591 patients were allocated to 3 groups: normal group, hyponatremia group, and hypernatremia group (Figure 1). All procedures performed in this study involving human participants were in accordance with the Declaration of Helsinki (as revised in 2013). The study was approved by ethics of Bioethics Committee of Beijing Friendship Hospital, Capital Medical University (No.: 2020-P2-065-01). Individual consent for this retrospective analysis was waived.

\section{Data collection}

Clinical data of patients at admission were collected, including age, gender, body mass index (BMI), body temperature, respiratory rate, heart rate, systolic blood pressure (SBP), diastolic blood pressure (DBP), $\mathrm{pH}$, arterial partial pressure of oxygen $\left(\mathrm{PaO}_{2}\right)$, arterial partial pressure of carbon dioxide $\left(\mathrm{PaCO}_{2}\right)$, concentration of hydrogen carbonate $\left(\mathrm{HCO}_{3}^{-}\right)$, potassium $\left(\mathrm{K}^{+}\right), \mathrm{Na}^{+}$, chloride ion $\left(\mathrm{Cl}^{-}\right)$, calcium ion $\left(\mathrm{Ca}^{2+}\right)$, alanine aminotransferase (ALT), aspartate aminotransferase (AST), direct bilirubin (D-BIL), total bilirubin (T-BIL), albumin, hemoglobin, D-Dimer, lactic acid, creatine kinase (CK), creatine kinase myocardial 
band (CK-MB), uric acid (UA), urinary $\mathrm{pH}(\mathrm{UpH})$, blood urea nitrogen (BUN), creatinine, acute physiology and chronic health evaluation (APACHE) score, sequential organ failure assessment (SOFA) score, and Glasgow score.

Previous history of nephropathy, diabetes, hyperlipidemia, hypertension, coronary heart disease, chronic heart failure, chronic obstructive pulmonary disease (COPD), cirrhosis, tumor, smoking, and drinking was recorded. The infection site was also recorded, including lung, biliary tract, urinary system, skin, soft tissue, abdominal, and pelvic cavity.

Organ dysfunctions including those of the respiratory system, circulatory system, liver, kidney, and coagulation system were also recorded.

\section{Definitions}

Normal serum $\mathrm{Na}^{+}$was $135-145 \mathrm{mmol} / \mathrm{L}$. Hypernatremia was defined as a concentration of $\mathrm{Na}^{+}$over $145 \mathrm{mmol} / \mathrm{L}$ (10). Hyponatremia was defined as a concentration of $\mathrm{Na}^{+}$under $135 \mathrm{mmol} / \mathrm{L}$.

The definition of sepsis was according to "Surviving Sepsis Campaign (2012)" as the presence of infection together with systemic manifestations (1).

The definition of AKI was referred to as the diagnostic criteria of Acute Kidney Injury Network (AKIN) and the Kidney Disease Improving Global Outcomes (KDGIO) $(14,15)$.

\section{Statistical analysis}

Continuous variables were expressed as mean \pm SD . Abnormally distributed data were expressed as median (interquartile range). Chi-square tests were used for comparison. Confounders and strong association variables were eliminated based on clinical experience. Univariate analysis was performed first, followed by multivariate analysis for hypernatremia, AKI, and death. Before multivariate analysis, the variables were co-linearly tested in a linear regression model, and variables without linear relationships were included in the multiple regression model. The receiver operating characteristic (ROC) curve was used in analyzing the predictive ability of $\mathrm{Na}^{+}$for AKI and death. A $\mathrm{P}$ value $<0.05$ was regarded as a significant difference.

\section{Results}

First, we compared the basic characteristics of patients with sepsis grouped by the level of serum $\mathrm{Na}^{+}$concentration. A total of 155 patients were hypernatremia and 96 patients were hyponatremia. At the same time, 340 patients displayed a normal range of $\mathrm{Na}^{+}$(Figure 1). As shown in Table 1, $\mathrm{PaCO}_{2}(\mathrm{P}=0.014)$, concentration of $\mathrm{Na}^{+}(\mathrm{P}<0.001)$ and $\mathrm{Cl}^{-}(\mathrm{P}<0.001), \mathrm{BUN}(\mathrm{P}<0.001)$, APACHE score $(\mathrm{P}<0.001)$, SOFA score $(\mathrm{P}<0.001)$, and Glasgow score $(\mathrm{P}<0.001)$ showed significant differences. The levels of T-BIL $(\mathrm{P}=0.049)$ and creatinine $(\mathrm{P}=0.049)$ displayed potential differences among the 3 groups. There were no differences found in age $(\mathrm{P}=0.270)$, gender $(\mathrm{P}=0.442)$, BMI $(\mathrm{P}=0.198)$, body temperature $(\mathrm{P}=0.197)$, respiratory rate $(\mathrm{P}=0.51)$, heart rate $(\mathrm{P}=0.359), \mathrm{SBP}(\mathrm{P}=0.925)$, $\mathrm{DBP}$ $(\mathrm{P}=0.106), \mathrm{pH}(\mathrm{P}=0.344), \mathrm{PaO}_{2}(\mathrm{P}=0.359)$, concentration of $\mathrm{HCO}_{3}^{-}(\mathrm{P}=0.086), \mathrm{K}^{+}(\mathrm{P}=0.392), \mathrm{Ca}^{2+}(\mathrm{P}=0.626)$, ALT $(\mathrm{P}=0.682)$, AST $(\mathrm{P}=0.562)$, T-BIL $(\mathrm{P}=0.950)$, albumin $(\mathrm{P}=0.270)$, hemoglobin $(\mathrm{P}=0.431)$, $\mathrm{D}$-Dimer $(\mathrm{P}=0.222)$, lactic acid $(\mathrm{P}=0.057), \mathrm{CK}(\mathrm{P}=0.894), \mathrm{CK}-\mathrm{MB}(\mathrm{P}=0.503)$, UA $(\mathrm{P}=0.298)$, and $\mathrm{UpH}(\mathrm{P}=0.627)$.

Then, the clinical features of patients with sepsis among 3 groups were further evaluated (Table 2). The AKI showed obvious differences $(\mathrm{P}=0.008)$, and patients with AKI had a much higher percentage of hypernatremia. Although the difference in death was not significant $(\mathrm{P}=0.078)$, the mortality of the hypernatremia group $(38.1 \%)$ was a little higher than hyponatremia $(31.3 \%)$ and normal group $(27.9 \%)$. The severity of sepsis seemed not to be different among 3 groups with quite a similar incidence rate $(\mathrm{P}=0.164)$. As for infection site, urinary infection $(\mathrm{P}=0.016)$, and abdominal and pelvic infection $(\mathrm{P}=0.010)$ showed significant differences. Moreover, the number of organ dysfunction was different statistically $(\mathrm{P}=0.009)$, and the hypernatremia group $(88.4 \%)$ tended to have multiple organ dysfunctions ( 2 or 3 ) in comparison with the hyponatremia $(70.8 \%)$ and normal group (75.3\%). Specifically, the difference in circulatory system dysfunction was statistically significant $(\mathrm{P}=0.048)$. By analysis of previous history, most diseases showed no difference except COPD $(\mathrm{P}=0.017)$ and cirrhosis $(\mathrm{P}=0.005)$.

Furthermore, we performed multivariate analysis for AKI in patients with hypernatremia. As shown in Table 3, SOFA score $(\mathrm{P}=0.040$; odds ratio $(\mathrm{OR})=1.261), \mathrm{BMI}(\mathrm{P}=0.041$; $\mathrm{OR}=1.229)$, $\mathrm{P}$ content $(\mathrm{P}=0.032 ; \mathrm{OR}=7.180)$, and $\mathrm{CK}-$ $\mathrm{MB}(\mathrm{P}=0.006$; $\mathrm{OR}=1.168)$ may be risk factors. Whereas, APACHE I score, Glasgow score, and CI content did not show significant differences.

Through multivariate analysis for death in patients with hypernatremia (Table 4), it was observed that AKI $(\mathrm{P}<0.001$; $\mathrm{OR}=6.850)$ and $\mathrm{P}$ content $(\mathrm{P}=0.027 ; \mathrm{OR}=3.676)$ indicated 
Table 1 Characteristics of patients with sepsis

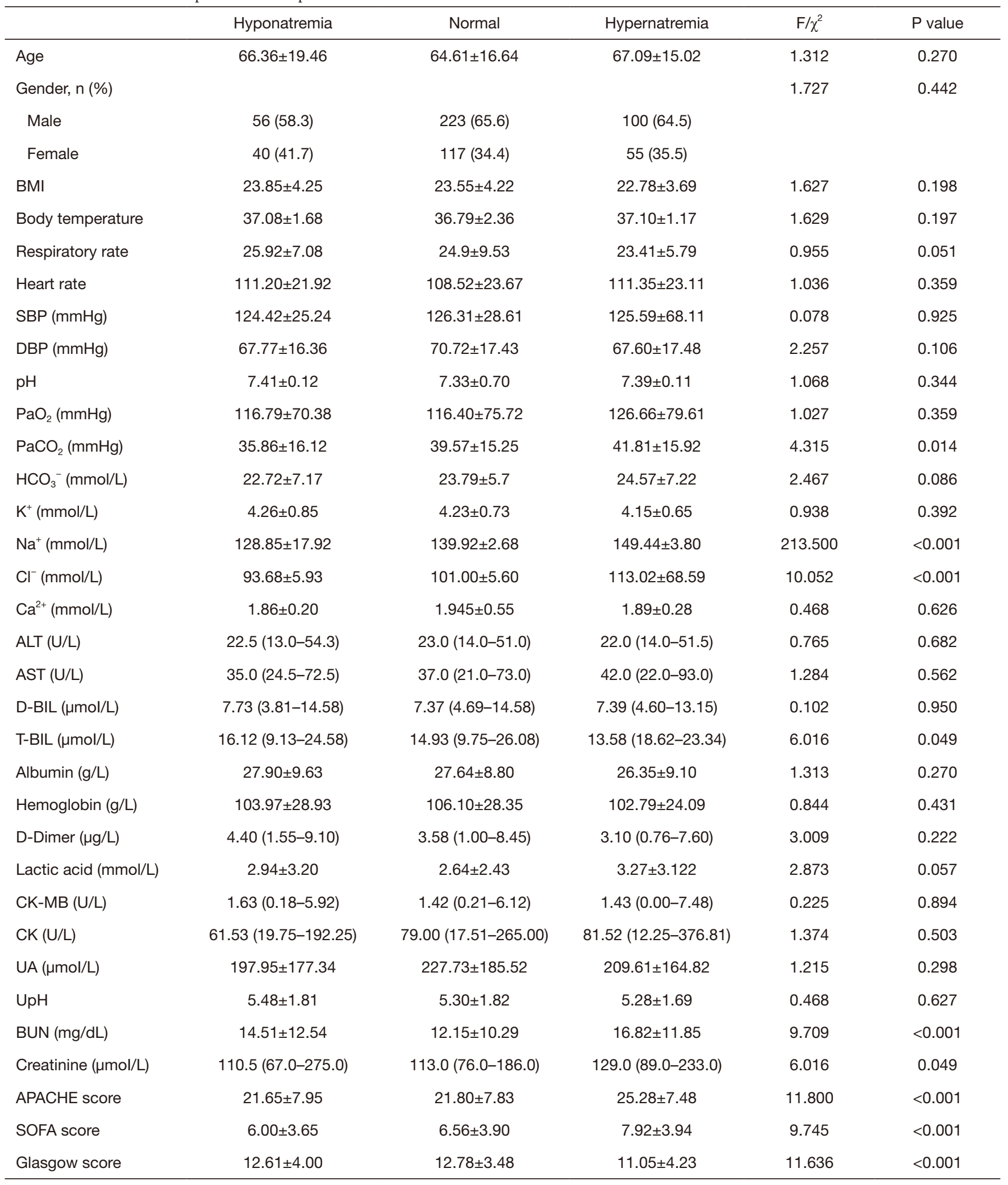


Table 2 Clinical features of patients with sepsis

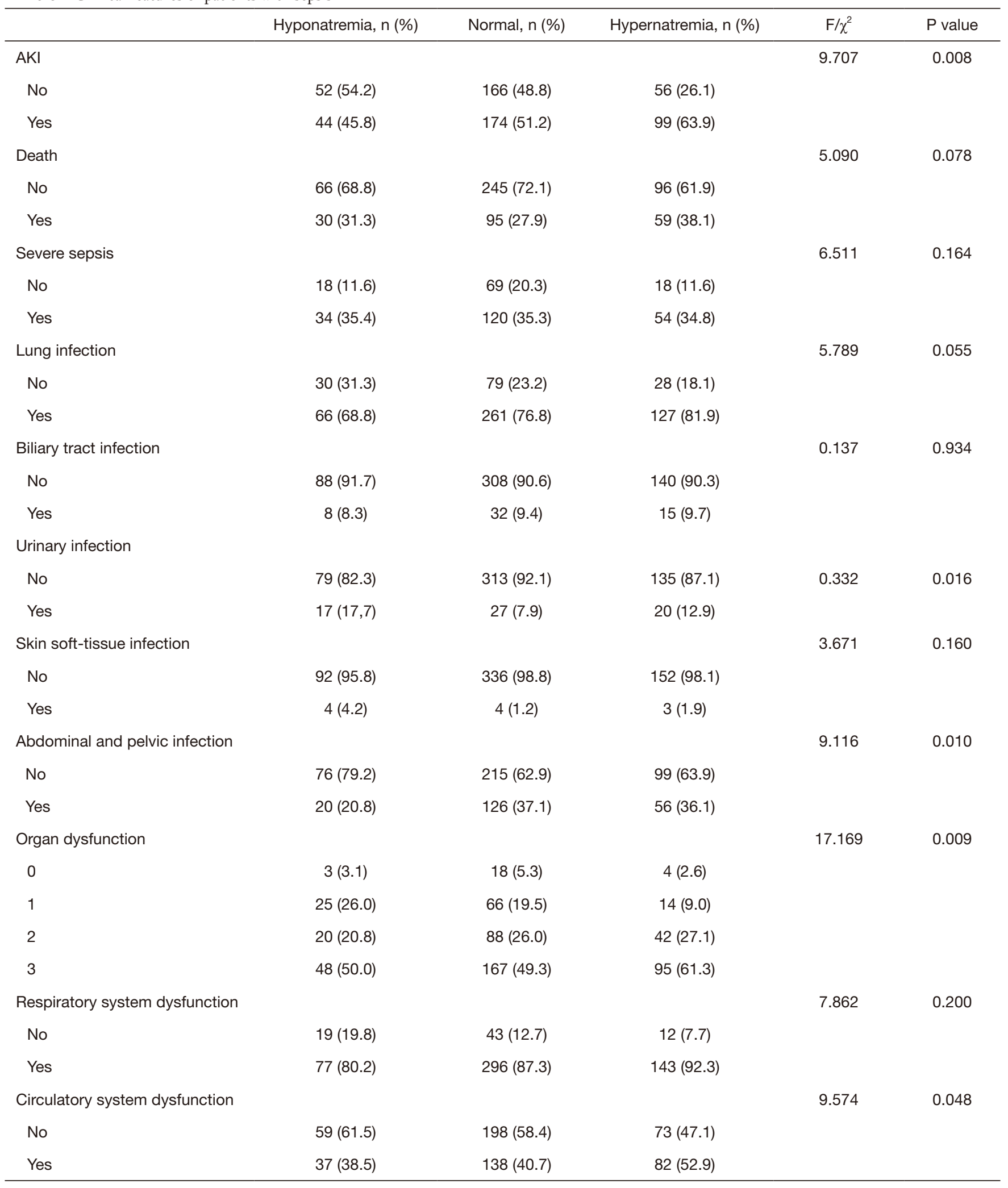

Table 2 (continued) 
Table 2 (continued)

\begin{tabular}{|c|c|c|c|c|c|}
\hline & Hyponatremia, n (\%) & Normal, n (\%) & Hypernatremia, n (\%) & $\mathrm{F} / \chi^{2}$ & $P$ value \\
\hline No & $59(61.5)$ & $226(66.7)$ & $107(69.0)$ & & \\
\hline Yes & $37(38.5)$ & $113(33.3)$ & $48(31.0)$ & & \\
\hline Kidney dysfunction & & & & 3.793 & 0.150 \\
\hline Yes & $48(50.0)$ & $186(54.9)$ & $96(61.9)$ & & \\
\hline Coagulation system dysfunction & & & & 2.444 & 0.295 \\
\hline No & $47(49.0)$ & $176(52.1)$ & $69(44.5)$ & & \\
\hline Yes & $49(51.0)$ & $162(47.9)$ & $86(55.5)$ & & \\
\hline Yes & $6(6.3)$ & $61(12.1)$ & $17(11.0)$ & & \\
\hline History of diabetes & & & & 1.633 & 0.442 \\
\hline No & $71(74.0)$ & $263(77.4)$ & $112(72.3)$ & & \\
\hline Yes & $25(26.0)$ & $77(22.6)$ & $43(27.7)$ & & \\
\hline History of hyperlipidemia & & & & 3.068 & 0.216 \\
\hline No & $91(94.8)$ & $318(93.5)$ & $139(89.7)$ & & \\
\hline Yes & $5(5.2)$ & $22(6.5)$ & $16(10.3)$ & & \\
\hline History of hypertension & & & & 1.101 & 0.577 \\
\hline History of chronic heart failure & & & & 1.341 & 0.511 \\
\hline No & $94(97.9)$ & $337(99.1)$ & $152(98.1)$ & & \\
\hline Yes & $2(2.1)$ & $3(0.9)$ & $3(1.9)$ & & \\
\hline History of COPD & & & & 8.175 & 0.017 \\
\hline No & $96(100)$ & 326 (95.9) & $154(99.4)$ & & \\
\hline Yes & $0(0)$ & $14(4.1)$ & $1(0.6)$ & & \\
\hline History of cirrhosis & & & & 10.792 & 0.005 \\
\hline No & $92(95.8)$ & 339 (99.7) & $149(96.1)$ & & \\
\hline Yes & $4(4.2)$ & $1(0.3)$ & $6(3.9)$ & & \\
\hline
\end{tabular}

Table 2 (continued) 
Table 2 (continued)

\begin{tabular}{|c|c|c|c|c|c|}
\hline & Hyponatremia, n (\%) & Normal, n (\%) & Hypernatremia, n (\%) & $F / \chi^{2}$ & $P$ value \\
\hline No & $92(95.8)$ & $304(89.4)$ & $136(87.7)$ & & \\
\hline Yes & $4(4.2)$ & $36(10.6)$ & 19 (12.3) & & \\
\hline Smoking history & & & & 1.761 & 0.414 \\
\hline Yes & $34(35.4)$ & $126(37.1)$ & $66(42.6)$ & & \\
\hline Drinking history & & & & 3.082 & 0.214 \\
\hline No & $76(79.2)$ & $246(72.4)$ & $107(69.0)$ & & \\
\hline Yes & $20(20.8)$ & $94(27.6)$ & $48(31.0)$ & & \\
\hline
\end{tabular}

AKI, acute kidney injury; COPD, chronic obstructive pulmonary disease.

Table 3 Multivariate analysis for AKI in patients with hypernatremia

\begin{tabular}{lcccc}
\hline & OR & $95 \%$ Cl & $\chi^{2}$ & P value \\
\hline SOFA & 1.261 & $1.011-1.574$ & 4.234 & 0.040 \\
APACHEI & 1.072 & $0.945-1.217$ & 1.167 & 0.280 \\
Glasgow & 1.034 & $0.870-1.229$ & 0.144 & 0.705 \\
BMI & 1.229 & $1.009-1.497$ & 4.196 & 0.041 \\
P & 7.180 & $1.189-43.348$ & 4.618 & 0.032 \\
Cl & 1.011 & $0.997-1.026$ & 2.401 & 0.121 \\
CK-MB & 1.168 & $1.046-1.306$ & 7.538 & 0.006 \\
\hline
\end{tabular}

$\mathrm{AKI}$, acute kidney injury; OR, odds ratio; $\mathrm{Cl}$, confidence interval; $\mathrm{BMI}$, body mass index; $\mathrm{CK}$, creatine kinase; APACHE, acute physiology and chronic health evaluation; SOFA, sequential organ failure assessment.

Table 4 Multivariate analysis for death in patients with hypernatremia

\begin{tabular}{lcccc}
\hline & OR & $95 \%$ Cl & $\chi^{2}$ & P value \\
\hline SOFA & 1.216 & $0.979-1.511$ & 3.124 & 0.077 \\
APACHE I & 1.083 & $0.962-1.220$ & 1.757 & 0.185 \\
Glasgow & 1.084 & $0.924-1.272$ & 0.972 & 0.324 \\
BMI & 1.063 & $0.906-1.247$ & 0.563 & 0.453 \\
P & 3.676 & $1.163-11.621$ & 4.915 & 0.027 \\
Cl & 0.999 & $0.958-1.042$ & 0.002 & 0.969 \\
CK-MB & 1.025 & $0.985-1.067$ & 1.502 & 12.207 \\
AKI & 6.850 & $2.328-20.161$ & $<0.001$ & \\
\hline
\end{tabular}

OR, odds ratio; $\mathrm{Cl}$, confidence interval; BMI, body mass index; $\mathrm{CK}$, creatine kinase; APACHE, acute physiology and chronic health evaluation; SOFA, sequential organ failure assessment. 
Table 5 Predictive ability of $\mathrm{Na}^{+}$for AKI and death

\begin{tabular}{lcccc}
\hline \multirow{2}{*}{ Predictors } & & \multicolumn{3}{c}{ ROC curves } \\
\cline { 2 - 5 } & Cut-off value & AUC & $95 \% \mathrm{Cl}$ & $\mathrm{P}$ value \\
\hline $\mathrm{Na}^{+}$for AKI & 141.75 & 0.586 & $0.541-0.632$ & $<0.001$ \\
$\mathrm{Na}^{+}$for death & 142.05 & 0.542 & $0.490-0.594$ & 0.104 \\
\hline
\end{tabular}

$\mathrm{Na}^{+}$, sodium; ROC, receiver operating characteristic; AUC, area under the curve; Cl, confidence interval; AKI, acute kidney injury.
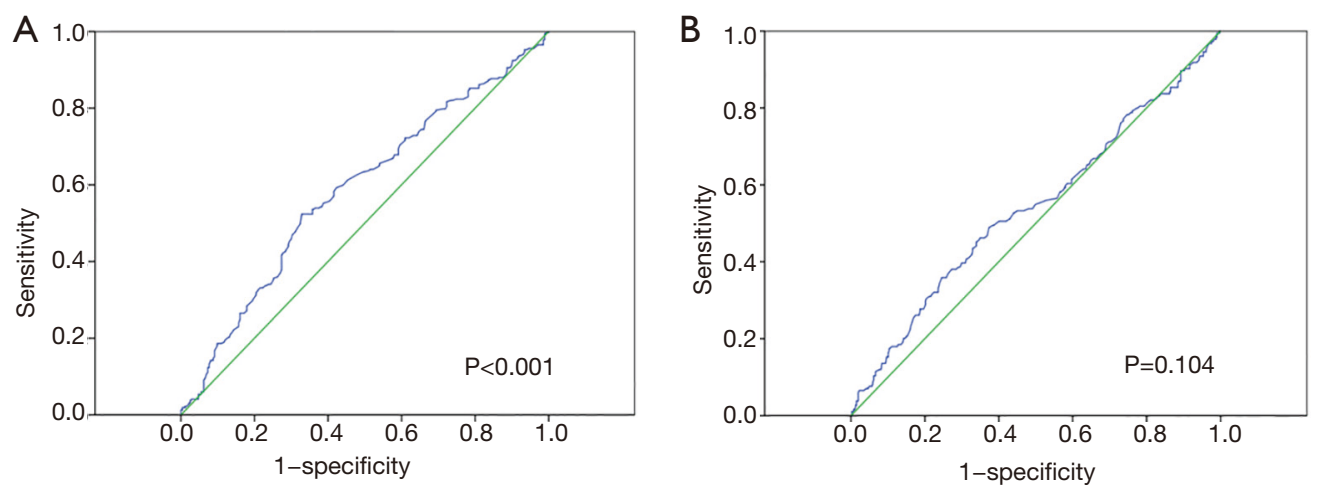

Figure 2 ROC curves. (A) The ROC curve of $\mathrm{Na}+$ for AKI in patients with sepsis; (B) The ROC curve of death for AKI in patients with sepsis. ROC, receiver operating characteristic; $\mathrm{Na}+$, sodium; AKI, acute kidney injury.

a significantly higher risk for death.

Finally, we studied the predictive ability of $\mathrm{Na}^{+}$for AKI and death (Table 5 and Figure 2). The $\mathrm{Na}^{+}$suggested a good predictive ability for $\mathrm{AKI}(\mathrm{P}<0.001$; area under the curve (AUC): 0.586) but not for death $(\mathrm{P}=0.104)$.

\section{Discussion}

From our results, the factors indicating kidney function such as BUN and creatinine were significantly different among the 3 groups, and were especially higher in the hypernatremia group. Besides, urinary infection further indicated a close relationship between AKI and sepsis. There are multiple factors involved in the occurrence of AKI, and the mechanism of increased mortality and morbidity risks associated with AKI remains to be elucidated. It was concluded by Bagshaw et al. that patients with septic AKI had an increased risk for death and a longer duration of hospitalization (16). Many researchers have regarded sepsis as a leading precipitant of AKI, while someone have reminded us not to ignore the likelihood of sepsis developing after AKI $(6,16,17)$. Mehta et al. looked at the relationship between AKI and sepsis using a multicenter and observational study and found that sepsis frequently develops after AKI and predicts a poor prognosis, with high mortality rates and a relatively long duration of hospitalization (17). Recently, Gomez et al. reported the metabolic reprogramming and tolerance in coordinating adaptive strategies during sepsis-induced AKI (18). As addressed by Honore et al., the relationship is more complicated than a simple question of chicken and egg, and a well-informed clinical trial in the future is warranted (19).

The major cause of hypernatremia is water depletion, resulting from either reduced intake or excessive loss (12). Thus, hypernatremia is usually regarded as a hypovolemic electrolyte disorder. From the experience of clinical practice, urinary loss is the most common reason. Notably, this circumstance is more prominent during recovery after AKI, and hypervolemic hypernatremia has been studied in this process $(12,20)$. Besides, it has also been highlighted that severe sepsis patients receiving $0.9 \%$ saline fluid resuscitation may acquire hypernatremia in an early process (21).

Corticosteroids are commonly used for treating sepsis $(22,23)$. The results of previous studies showed a mild increase in $\mathrm{Na}^{+}$level and increased the risk of hypernatremia with high-certainty evidence (22-25). It is suggested that the 
administration of corticosteroids is associated with reduced 28-day mortality compared with placebo use or standard supportive care (24). Another large randomized controlled trial (RCT), the Activated Protein C and Corticosteroids for Human Septic Shock (APROCCHSS) trial, showed that hydrocortisone plus fludrocortisone of low doses reduced 90-day mortality among patients with septic shock (26). However, the Adjunctive Corticosteroid Treatment in Critically Ill Patients with Septic Shock (ADRENAL) trial showed a significantly different result that the mortality was not decreased (27). Whether the subsequent hypernatremia, in turn, influences the effect of corticosteroids remains to be further studied. As suggested in a prospective study by Levy et al., the muscle $\mathrm{Na}^{+} \mathrm{K}^{+}$ATPase activity may raise lactate concentrations in septic shock (28). We think that electrolyte disorder inside the body may account for the predictive ability of $\mathrm{Na}^{+}$for AKI. Mendes et al. regarded predialysis hypernatremia as a prognostic marker in AKI in need of renal replacement therapy (29). Wu et al. reported serum $\mathrm{Na}^{+}$as a reliable and validated predictor for mortality in enteric fistula patients complicated with sepsis (30). However, inconsistent with their conclusion, $\mathrm{Na}^{+}$did not indicate a meaningful predictive ability for death in patients with sepsis combined with AKI. Metabolic disturbances, including hypernatremia, hypercapnia, and elevated lactates, caused by AKI in sepsis were also associated with encephalopathy (31).

A limitation of this study was the retrospective analysis of data from a single center. Multi-center studies should be conducted in the future to further comfirm the conclusions of this study. We mainly focused on the risk factors for AKI in patients with sepsis but have not compared the treatment yet. To complete an in-depth study, the evaluation of biomarkers will be involved in our future research.

\section{Conclusions}

Hypernatremia is independently associated with an increased risk and has a predictive ability of AKI in patients with sepsis.

\section{Acknowledgments}

Funding: This work was supported by the Beijing Municipal Administration of Hospitals Clinical Medicine Development of Special Funding (ZYLX201802).

\section{Footnote}

Reporting Checklist: The authors have completed the STARD reporting checklist. Available at http://dx.doi.org/10.21037/ apm-21-792

Data Sharing Statement: Available at http://dx.doi. org/10.21037/apm-21-792

Conflicts of Interest: All authors have completed the ICMJE uniform disclosure form (available at http://dx.doi. org/10.21037/apm-21-792). The authors have no conflicts of interest to declare.

Ethical Statement: The authors are accountable for all aspects of the work in ensuring that questions related to the accuracy or integrity of any part of the work are appropriately investigated and resolved. All procedures performed in this study involving human participants were in accordance with the Declaration of Helsinki (as revised in 2013). The study was approved by ethics of Bioethics Committee of Beijing Friendship Hospital, Capital Medical University (No.: 2020-P2-065-01). Individual consent for this retrospective analysis was waived.

Open Access Statement: This is an Open Access article distributed in accordance with the Creative Commons Attribution-NonCommercial-NoDerivs 4.0 International License (CC BY-NC-ND 4.0), which permits the noncommercial replication and distribution of the article with the strict proviso that no changes or edits are made and the original work is properly cited (including links to both the formal publication through the relevant DOI and the license). See: https://creativecommons.org/licenses/by-nc-nd/4.0/.

\section{References}

1. Dellinger RP, Levy MM, Rhodes A, et al. Surviving Sepsis Campaign: international guidelines for management of severe sepsis and septic shock, 2012. Intensive Care Med 2013;39:165-228.

2. Hotchkiss RS, Moldawer LL, Opal SM, et al. Sepsis and septic shock. Nat Rev Dis Primers 2016;2:16045.

3. Dombrovskiy VY, Martin AA, Sunderram J, et al. Rapid increase in hospitalization and mortality rates for severe sepsis in the United States: a trend analysis from 1993 to 
2003. Crit Care Med 2007;35:1244-50.

4. Linde-Zwirble WT, Angus DC. Severe sepsis epidemiology: sampling, selection, and society. Crit Care 2004;8:222-6.

5. Hoste EA, Bagshaw SM, Bellomo R, et al. Epidemiology of acute kidney injury in critically ill patients: the multinational AKI-EPI study. Intensive Care Med 2015;41:1411-23.

6. Uchino S KJ, Bellomo R, Doig GS, Morimatsu H, Morgera S, Schetz M, Tan I, Bouman C, Macedo E, Gibney N, Tolwani A, Ronco C; Beginning and Ending Supportive Therapy for the Kidney (BEST Kidney) Investigators. Acute renal failure in critically ill patients: a multinational, multicenter study. JAMA 2005;294:813-8.

7. Bellomo R, Kellum JA, Ronco C, et al. Acute kidney injury in sepsis. Intensive Care Med 2017;43:816-28.

8. Ronco C, Bellomo R, Kellum JA. Acute kidney injury. The Lancet 2019;394:1949-64.

9. Liu J, Xie H, Ye Z, et al. Rates, predictors, and mortality of sepsis-associated acute kidney injury: a systematic review and meta-analysis. BMC Nephrol 2020;21:318.

10. Collins NM, Carrick JB, Russell CM, et al. Hypernatraemia in 39 hospitalised foals: clinical findings, primary diagnosis and outcome. Australian Veterinary Journal 2018;96:385-9.

11. Hoorn EJ, Betjes MG, Weigel J, et al. Hypernatraemia in critically ill patients: too little water and too much salt. Nephrol Dial Transplant 2008;23:1562-8.

12. Sam R, Hart P, Haghighat R, et al. Hypervolemic hypernatremia in patients recovering from acute kidney injury in the intensive care unit. Clin Exp Nephrol 2012;16:136-46.

13. Lindner G, Funk GC, Schwarz C, et al. Hypernatremia in the critically ill is an independent risk factor for mortality. Am J Kidney Dis 2007;50:952-7.

14. Mehta RL, Kellum JA, Shah SV, et al. Acute Kidney Injury Network: report of an initiative to improve outcomes in acute kidney injury. Crit Care 2007;11:R31.

15. Bellomo R, Ronco C, Kellum JA, et al. Acute renal failure - definition, outcome measures, animal models, fluid therapy and information technology needs: the Second International Consensus Conference of the Acute Dialysis Quality Initiative (ADQI) Group. Crit Care 2004;8:R204-12.

16. Bagshaw SM, Uchino S, Bellomo R, et al. Septic acute kidney injury in critically ill patients: clinical characteristics and outcomes. Clin J Am Soc Nephrol 2007;2:431-9.
17. Mehta RL, Bouchard Je, Soroko SB, et al. Sepsis as a cause and consequence of acute kidney injury: Program to Improve Care in Acute Renal Disease. Intensive Care Med 2011;37:241-8.

18. Gomez H, Kellum JA, Ronco C. Metabolic reprogramming and tolerance during sepsis-induced AKI. Nat Rev Nephrol 2017;13:143-51.

19. Honore PM, Jacobs R, Boer W, et al. Sepsis and AKI: more complex than just a simple question of chicken and egg. Intensive Care Med 2011;37:186-9.

20. Sarahian S, Pouria MM, Ing TS, et al. Hypervolemic hypernatremia is the most common type of hypernatremia in the intensive care unit. Int Urol Nephrol 2015;47:1817-21.

21. Van De Louw A, Shaffer C, Schaefer E. Early intensive care unit-acquired hypernatremia in severe sepsis patients receiving $0.9 \%$ saline fluid resuscitation. Acta Anaesthesiol Scand 2014;58:1007-14.

22. Annane D, Bellissant E, Bollaert PE, et al. Corticosteroids for treating sepsis. Cochrane Database Syst Rev 2015;CD002243.

23. Annane D, Bellissant E, Bollaert PE, et al. Corticosteroids for treating sepsis in children and adults. Cochrane Database Syst Rev 2019;12:CD002243.

24. Fang F, Zhang Y, Tang J, et al. Association of Corticosteroid Treatment With Outcomes in Adult Patients With Sepsis: A Systematic Review and Metaanalysis. JAMA Intern Med 2019;179:213-23.

25. Rochwerg B, Oczkowski SJ, Siemieniuk RAC, et al. Corticosteroids in Sepsis: An Updated Systematic Review and Meta-Analysis. Crit Care Med 2018;46:1411-20.

26. Annane D, Renault A, Brun-Buisson C, et al. Hydrocortisone plus Fludrocortisone for Adults with Septic Shock. N Engl J Med 2018;378:809-18.

27. Venkatesh B, Finfer S, Cohen J, et al. Adjunctive Glucocorticoid Therapy in Patients with Septic Shock. N Engl J Med 2018;378:797-808.

28. Levy B, Gibot S, Franck P, et al. Relation between muscle $\mathrm{Na}+\mathrm{K}+$ ATPase activity and raised lactate concentrations in septic shock: a prospective study. Lancet 2005;365:871-5.

29. Mendes RS, Soares M, Valente C, et al. Predialysis hypernatremia is a prognostic marker in acute kidney injury in need of renal replacement therapy. J Crit Care 2015;30:982-7.

30. Wu Y, Ren J, Wang G, et al. Serum Sodium: A Reliable 
and Validated Predictor for Mortality in Enteric Fistula Patients Complicated with Sepsis. J Invest Surg 2015;28:131-9.

31. Sonneville R, de Montmollin E, Poujade J, et al. Potentially modifiable factors contributing to sepsis-

Cite this article as: Zhi D, Lin J, Dong L, Ji X, Zhuang H, Liu Z, Liu J, Duan M. Risk predictive role of hypernatremia for occurrence of sepsis-induced acute kidney injury. Ann Palliat Med 2021;10(4):4705-4715. doi: 10.21037/apm-21-792 associated encephalopathy. Intensive Care Med 2017;43:1075-84.

(English Language Editor: J. Jones) 